Rev. Saude públ., S. Paulo

$12: 250-7,1978$

\title{
ESTUDO COMPARATIVO ENTRE OS MÉTODOS DE COLORAÇÃO FLUORESCENTE E ZIEHL-NEELSEN EM SECREÇOES PULMONARES*
}

\author{
Rinaldo Niero** \\ Maria José Andrade Bello** \\ Joselita Silvia Berardi Possas **
}

\begin{abstract}
RSPUB9/414
NiERO, R. et al. Estudo comparativo entre os métodos de coloração fluorescente e Ziehl-Neelsen em secreçóes pulmonares. Rev. Saúde públ., S. Paulo, 12: $250-7,1978$.

RESUMO: Foi realizada uma comparação entre os métodos de microscopia fluorescente e Ziehl-Neelsen, para evidenciação de bacilos álcool-ácido resistentes em secreçóes pulmonares. A sensibilidade e especificidade de cada método foram avaliadas em função da cultura, mostrando que o método fluorescente apresentou uma diferença de sensibilidade de $7,28 \%$ e $3,17 \%$ para as áreas estudadas. As diferenças auanto a especificidade foram despreziveis. Houve uma associação positiva entre ambos os métodos.
\end{abstract}

UnITERMos: Tuberculose, diagnóstico. Microscopia fluorescente.

I N T RODUÇAO

O diagnóstico bacteriológico da tuberlose, através de laboratório, continua a depender primariamente de duas atividades: o exame microscópico direto (baciloscopia) e a cultura dos diversos materiais biológicos. Entre eles, o primeiro, por ser o mét jo mais viável e exequivel, tem sido o r.ai.; comumente empregado.

Dos métodos de coloração conhecidos para a identificação de bacilos álcool-ácidos resistentes em secreções pulmonares, destacam-se $o$ de Ziehl-Neelsen, introduzido em 1882 e que tem sido considerado o método de rotina universalmente aceito, e o método fluorescente preconizado por Hagenann desde 1937.

Inúmeras modificações têm sido efetuadas desde a introdução dos métodos originais e que visaram basicamente a descoloração, a contracoloração (fundo) e a fonte de energia luminosa Kuper e May ${ }^{10}$ (1960), Truant 18 (1962), Silver e col.16 (1966), Suassuna e Pinheiro ${ }^{17}$ (1973).

Além das modificações de ordem técnica, inúmeros trabalhos comparativos entre os dois métodos foram realizados, mostrando que o método fluorescente revela um percentual maior de positividade - Bogen ${ }^{3}$

\footnotetext{
* Apresentado ao XVIIIo Congresso Nacional de Tuberculose e Doenças Respiratórias - Balneário de Camboriu, SC - Novembro, 1977.

* Do Departamento de Epidemiologia da Faculdade de Saúde Pública da USP -- Av. Dr. Amaldo, 715 - 01255 - Săo Paulo, SP - Brasil.
} 
NIERO, R. et al. Estuio comparativo entre os métodos de coloração fluorescente e ZiehlNeelsen em secreçōes pulmonares. Rev. Saúde públ., S. Paulo, 12:250-7, 1978

(1941), Freiman e Mokotoff 4 (1943), Truant 1. (1962), Koch e Cote ${ }^{9}$ (1965). Silver e col. 16 (1966), Narain 1. (1971). Já Oliva 1.5 (1958) notou que o método fluorescente fornece erros por excesso, sendo portanto um método mais sensivel, porém pouco específico. Outros autores, como Hirsh e col.s (1958), corando a mesma lâmina pelo método fluorescente e pelo de Ziehl-Neelsen, concluíram pela igualdade de resultados nos dois metodos. O trabalho de Lind 11 (1949) mostrou que não existiu vantagem entre o método fluorescente e o de Ziehl-Neelsen e que o primeiro deu mais falsos positivos. Quanto às micobatérias atipicas, Andrade 1 (1951) salientou a ausência de fluorescência em cepas de $M$. ranae, $M$. piscium e $M$. paratuberculosis, obtidas de culturas. Joseph e col.; (1967) e Joseph e Houk \& (1968) notaram que a maioria das cepas do grupo IV de Runyon (micobactérias de crescimento rápido) foram negativas quando coradas pela auramina-rhodamina.

A adição de rhodamina à auramina foi introduzida por Hughes em 1946. Matthaeir. (1950) fez algumas modificações técnicas, aumentando a concentração dos corantes. Pusteriormente, Kuper e May ${ }^{1 \prime}$ (1960) aperfeiçoaram a técnica e estabeleceram o tempo de contracoloração da solução de permanganato de potássio. Finalmente Silver e col. ${ }^{16}$ (1966) introduziram algumas modificaçōes no corante e no tempo de coloração, que são as usadas ultimamente.

A coloração fluorescente, segundo a maioria dos autores, não é mais dificil e tem sido descrita como um método simples, principalmente quando usado na coloração de tecidos e material bacteriológico: Mcclure ${ }^{13}$ (1953), Kuper e May 10 (1960), Truant 1s (1962) e Silver e col.1: (1966). O custo da aparelhagem, talvez, seja a única dificuldade para a introdução de tal método na rotina dos diversos laboratórios, embora pode-se notar, freqüentemente, que inumeros deles, que possuem tal aparelhagem, não se preocupam em introduzir 0 método fluorescente na rotina diária de baciloscopia de secreções pulmonares.

Baseados nos diferentes resultados obtidos através dos vários estudos comparativos existentes, resolvemos realizar uma comparaçāo entre a coloraçāo fluorescente e o tradicional Ziehl-Neelsen, em secreções pulmonares, obtidas de sintonáticos respiratórios que procuraram os serviços de saude para diagnóstico da tuberculose pulmonar em duas áreas programáticas. Alguns aspectos relativos ao método fluorescente propriamente dito foram também salientados.

\section{MATERIAL E METODOS}

Foram utilizadas amostras de escarro de 294 e 301 sintomáticos respiratórios que compareceram, respectivamente, ao Serviço de Tisiologia do Centro de Saúde "Geraldo de Paula Souza" Área (1) e do Dispensário de Tuberculose do Ipiranga da Associação dos Sanatorinhos de "Campos do Jordão" Área (2) para diagnóstico da tuberculose pulmonar.

O material foi coletado no próprio domicilio, sendo recomendada a primeira amostra matinal, que era trazida imediatamente após a colheita, ao laboratório.

Foram realizados dois esfregaços correspondentes a cada material e corados respectivamente pelo método de Ziehl-Neelsen e fluorescente. $O$ método fluorescente obedeceu ao preconizado por Kuper e May ${ }^{\circ}$ (1960) e modificado por Silver e col. ${ }^{1:}$ (1966) que consiste no seguinte:

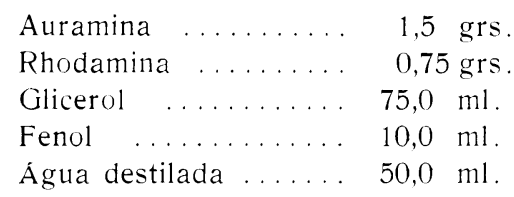

A coluração foi elaborada a $37^{\circ} \mathrm{C}$ por 30 min. A descoloração foi efetuada por 10 min. com a seguinte solução:

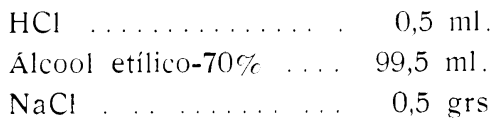


NIERO. R. et al. Estuio comparativo entre os métodos de coloração fluorescente e ZiehINeelsen em sccreçōes pulmonares. Rev. Saúde públ., S. Paulo, 12:250-7, 1978.

A contracoloração (fundo) foi feita com solução de permanganato de potássio $0,5 \%$, por 2 min.

Os esfregaços corados pelo método de Ziehl-Neelsen foram examinados por técnicos diferentes, pertencentes respectivamente às Áreas (1) e (2). Já os esfregaços corados pelo método fluorescente foram examinados por um terceiro técnico e confirmados pelo técnico da Área (1).

A aparelhagem empregada para coloração fluorescente foi um microscópio "NIKON" modelo F.L.S., binocular, com objetivas acromáticas de $10 \times 0,25,40 \times$ 0,65 e $100 \times 0,65$ (imersão), diafragma iris, oculares de grande campo, condensador cardióide de campo escuro e sistema de iluminação com combustão de mercúrio HBO 200. O sistema de filtros consistiu em filtros excitadores $\mathrm{BV} 3 \mathrm{~mm}$ e filtros de absorção amarelo Y51.

A descontaminação do material foi efetuada através do método de Darzins e a cultura foi realizada em 3 tubos de meio de Lowesnsteins-Jensen, observados semanalmente e mantidos durante 60 dias, nos casos negativos.

\section{RESULTADOS E DISCUSSÃO}

Os dados referentes a ambas as áreas foram analisados para se conhecer a associação existente entre os métodos de coloração fluorescente e Ziehl-Neelsen. A sensibilidade e especificidade de cada método foram avaliadas frente aos resultados obtidos das culturas das amostras em meio seletivo para crescimento de micobactérias.
De acordo com a tabela de associação, temos para ambas as áreas:

\begin{tabular}{|c|c|c|c|}
\hline $\begin{array}{l}\text { Ziehl- } \\
\text { Neelzen } \\
\text { cência }\end{array}$ & + & - & Total \\
\hline Positiva & $a$ & b & $a+b$ \\
\hline Negativa & $c$ & $\mathrm{~d}$ & $c+d$ \\
\hline Total & $a+c$ & $b+d$ & $a+b+c+d$ \\
\hline
\end{tabular}

onde $x^{2}$ pode ser calculado através da fórmula salientada em Berquó 2 (1970):

$$
x_{c}^{2}=\frac{(1 a d-b c-n / 2)^{2} n}{(a+b)(c+d)(a+c)(b+d)}
$$

Os resultados da associação são mostrados respectivamente nas Tabelas 1 e 2 .

TABELA 1

Número de casos segundo os resultados apresentados pelos métodos de ZiehlNeelsen e fluoresente na Área (1), São Paulo-1977.

\begin{tabular}{lrrr}
$\begin{array}{c}\text { Ziehl- } \\
\text { Neelsen }\end{array}$ & + & & Total \\
$\begin{array}{l}\text { Fluores- } \\
\text { cente }\end{array}$ & & & \\
\hline Positivo & 42 & 5 & 47 \\
Negativo & 0 & 247 & 247 \\
\hline Total & 42 & 252 & 294 \\
\hline
\end{tabular}

$$
x^{\prime 2}=\frac{\left(|42 \times 247-5 \times 0|-\frac{294}{2}\right)^{2} \times 294}{(42)(252)(47)(247)}=257,51
$$

$\mathrm{x}^{2}$ critico $=10,827$ com um grau de liberdade e $\alpha=0,001 \%$. 
NIERO, R. et al. Estulo comparativo entre os métodos de coloraçåo fluorescente e Ziehl-

Neelsen em secrecōes pulmonares. Rev. Saúde públ., S. Paulo, 12:250-7. 1978.

TABELA 2

Número de casos segundo os resultados apresentados pelos métodos de ZiehlNeelsen e fluorescente na Área (2), São Paulo-1977.

\begin{tabular}{lrr|c}
\hline $\begin{array}{l}\text { Fluores- } \\
\text { cente }\end{array}$ & $\begin{array}{c}\text { Ziehl- } \\
\text { Neelsen }\end{array} \mid+$ & - & Total \\
\hline $\begin{array}{lrrr}\text { Positivo } \\
\text { Negativo }\end{array}$ & 39 & 6 & 45 \\
\hline Total & 40 & 261 & 301 \\
\hline
\end{tabular}

$$
x^{2}=\frac{(|39 \times 255-6 \times 1|-301 / 2)^{2} \times 294}{(45)(40)(261)(256)}=247,27
$$

$\mathrm{X}^{2}$ critico $=10,827 \mathrm{com}$ um grau de liberdade e $\alpha=0,001 \%$

mostrando que em ambas as áreas existe uma associação positiva, ou seja, que ambos os métodos podem ser usados indiferentemente.

Verificando-se que existiu uma associação positiva, passou-se então ao teste da sensibilidade (S) e especificidade (E) dos métodos. Os resultados positivos e negativos verificados pelos métodos de coloração foram confrontados com a cultura, por ser o método de maior sensibilidade e especificidade. A sensibilidade (S) foi calculada mediante a fórmula:

$$
S=\frac{a}{a+c} \times 100
$$

e a especificidade (E) foi calculada mediante a fórmula:

$$
E=\frac{d}{b+d} \times 100
$$

As Tabelas 3 e 4 mostram tais comparaçĩes:
TABELA 3

Número de casos segundo resultados obtidos pela cultura e método de Ziehi-Neelsen na Área (1), São Paulo-1977.

\begin{tabular}{lrrr}
\hline Ziehl & & & Total \\
\hline Positivo & 40 & 2 & 42 \\
Negativo & 15 & 237 & 252 \\
\hline Total & 55 & 239 & 294 \\
\hline$S=72,72 \%$ & & $E=$ & $99,16 \%$
\end{tabular}
obtidos pela cultura e método fluorescente Área (1), São Paulo-1977.

\begin{tabular}{l|rrr}
\hline Cultura & & & \\
\hline & + & & Total \\
\hline Fluorescente & & & \\
\hline Positivo & 44 & 3 & 47 \\
Negativo & 11 & 236 & 247 \\
\hline Total & 55 & 239 & 294 \\
\hline$S=80,0 \%$ & & E $=98,74 \%$
\end{tabular}


NIERo, R. et al. Estudo comparativo entre os métodos de coloração fluorescente e ZiehlNeelsen em secreçōes pulmonares. Rev. Saúde públ., S. Paulo, 12:250-7, 1978.

TABELA 5

Número de casos segundo resultados obtidos pela cultura e método de ZiehlNeelsen na Área (2), São Paulo-1977.

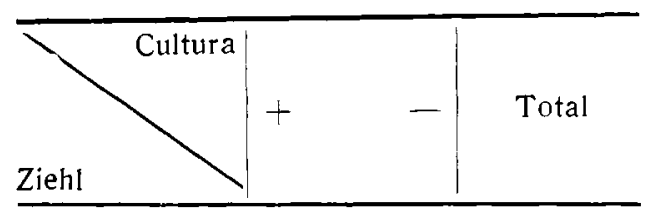

\begin{tabular}{llrc} 
Positivo & 32 & 7 & 39 \\
Negativo & 31 & 231 & 262 \\
\hline Total & 63 & 238 & 301 \\
\hline$S=50,79 \%$ & & $\mathrm{E}=97,05 \%$
\end{tabular}

TABELA 6

Número de casos segundo resultados obtidos pela cultura e método fluorescente Área (2), São Paulo-1977.

\begin{tabular}{lrr|c}
\hline Cluorescente & & & \\
\hline Positivo & 34 & 10 & 44 \\
Negativo & 29 & 228 & 257 \\
\hline Total & 63 & 238 & 301 \\
\hline$S=53,96 \%$ & & \\
\hline
\end{tabular}

As Tabelas 3 e 4 mostram os resultados obtidos comparando-se as coloraçōes de Ziehl-Neelsen e fluorescente na Área (1).

$\mathrm{Na}$ Tabela 3 verificou-se que os casos positivos, com respectiva cultura positiva, fornecidos pelo método de Ziehl-Neelsen, totalizaram 40 casos; 15 casos foram negativos ao método e positivos à cultura, dando portanto uma sensibilidade frente à cultura de $72,72 \%$. O método fluorescente (Tabela 4) forneceu-nos 44 casos positivos tanto à baciloscopia como à cultura, e 11 casos negativos à microscopia e positivos à cultura, dando uma sensibilidade frente à cultura de $80,0 \%$. Portanto, houve uma diferença de sensibilidade entre os métodos de $7,28 \%$.

Houve 2 e 3 casos positivos respectivamente à coloração de Ziehl-Neelsen e à fluorescente e negativos à cultura ("falsos positivos") dando uma especificidade quando comparados à cultura de $99,16 \%$ e $98,74 \%$, com uma diferença de $0,42 \%$ entre eles.

Os resultados obtidos na Área (2), mostram 32 Ziehl positivos, com cultura positiva e 31 casos Ziehl negativos e cultura positiva (Tabela 5) resultando numa sensibilidade do método frente à cultura de $50,79 \%$. Já o método fluorescente forneceu 34 positivos com cultura positiva e 29 casos negativos com cultura positiva, resultando numa sensibilidade do método frente à cultura de 53,96\%. Verificou-se, portanto, uma diferença de sensibilidade de $3,17 \%$ em favor do método fluorescente. A especificidade frente à cultura foi de $97,05 \%$ e $95,79 \%$ respectivamente para os métodos de Ziehl-Neelsen e fluorescente.

Comparando-se a sensibilidade de ambos os métodos, de acordo com a respectiva área, verificou-se que a diferença de sensibilidade do método de Ziehl-Neelsen da Área (1) para a Área (2) foi de $21,93 \%$. A diferença observada quanto ao método fluorescente entre as duas áreas foi de $26,04 \%$. Embora não sejam objeto deste estudo, tais diferenças são significativas e devem ser posteriormente pesquisadas; talvez essa diferença possa ser atribuída à amostra (material inadequado, como por exemplo: saliva) ou à seleção de pacientes, com período de duração de sintomatologia respiratória inferior ao preconizado. Foram afastadas hipóteses quanto à técnica de coloração e microscopia, porque as sensibilidades dos métodos de Ziehl e fluorescente estiveram em torno de $72,72 \%$ e $80,0 \%$ na Área (1) e $50,79 \%$ e $53,96 \%$ na Área (2).

Os resultados encontrados nas Áreas (1) e (2) estão próximos dos obtidos por Freiman e Mokotoff 4 (1943), que encon- 
NIERO, R. et al. Estudo comparativo entre os métodos de coloração fluorescente e ZiehlNeelsen em secreções pulmonares. Rev. Saúde públ., S. Paulo, 12:250-7, 1978.

traram diferenças de positividade em favor do método fluorescente de 3 e $4 \%$ para os exames direto e homogeneizado. Koch e Cote $\$$ (1965) demonstraram vantagem de $8,2 \%$ a favor da fluorescência em secreções pulmonares. Narain e col.14 (1971) obtiveram uma diferença de $10 \%$ em amostras de 12 horas. Discordante destes resultados, estão apenas Bogen ${ }^{3}$ (1941), que encon- trou diferenças de positividade em maior grau, seja, 20\%; Hirsh e col. 5 (1958) e Holst e col." (1959), que concluiram não haver diferenças entre os dois métodos.

Nas amostras positivas o grau de intensidade bacilar variou segundo as áreas, nas seguintes proporções, como mostra a Tabela 7 .

TABELA 7

Número e percentual de casos segundoa intensidade bacilar e àrea de estudo, São Paulo-1977.

\begin{tabular}{cc|c|c|c}
\hline $\begin{array}{r}\text { Intensidade } \\
\text { bacilar }\end{array}$ & + & ++ & +++ & Total \\
Área & $10-24,39 \%$ & $20-48,78 \%$ & $11-26,83 \%$ & $41-100 \%$ \\
1 & $9-23,08 \%$ & $18-46,15 \%$ & $12-30,77 \%$ & $39-100 \%$ \\
\hline Total & $19-23,75 \%$ & $38-47,50 \%$ & $23-28,75 \%$ & $80-100 \%$ \\
\hline
\end{tabular}

Notou-se que as intensidades bacilares distribuiram-se respectivamente nas Áreas (1) e (2) em números e percentuais praticamente idênticos.

Quanto à observação das lâminas coradas, o método de Ziehl-Neelsen preconiza o uso de condensador de campo claro e objetiva de imersão, obrigando o observador a um tempo maior de leitura, em virtude do grande número de elementos celulares presentes e que são corados em azul. $O$ método fluorescente usa condensador de campo escuro e a observação das lâminas contracoradas com permanganato de potássio mostram, geralmente, apenas os bacilos álcool-ácido resistentes, cuja imagem amarelo-avermelhada fluorescente é vista sobre um fundo negro.

O encontro de bacilos álcool-ácido resistentes em secreções pulmonares cuja intensidade bacilar varia entre $++\mathrm{e}+++$ é instantâneo (cerca de 10 segundos), en- quanto que no Ziehl-Neelsen este tempo varia de 2 a 5 min. Isto se deve ao uso de objetiva de pequeno aumento, que tem uma amplitude de campo 10 vezes maior quando comparada à objetiva de imersã).

Nos materiais paucibacilares este tempo de observação das lâminas, pelo método de Ziehl-Neelsen, aumenta sensivelmente. Conseguiu-se percorrer de 1.000 a 2.000 campos microscópicos em menos de $3 \mathrm{~min}$. Isto torna o método fluorescente recomendável a laboratórios que tenham uma rotina diária não inferior a 50 lâminas. Temse necessidade, no entanto, de observar um número considerável de lâminas (cerca de 500 ) antes de se colocar o método em uso. Isto permitirá ao observador ganhar confiança na identificação dos bacilos em pequeno aumento. Tal treinamento proporcionará ao observador decidir entre artefato e bacilo, evitando-se assim cons- 
NIERO, R. et al. Estudo comparativo entre os métodos de coloração fluorescente e ZiehiNeelsen em secreções pulmonares. Rev. Saúde públ., S. Paulo, 12:250-7, 1978.

tantes reconfirmaçóes em aumentos maiores e conseqüente perda de tempo.

O método é simples e a coloração não trouxe nenhum problema para ser implantada. Na focalização da lâmina usou-se sobre o condensador uma gota de glicerol ou óleo mineral, que mostraram não emitir fluorescência. Os filtros excitadores BV (de 3 e 4mm) foram empregados juntos ou isoladamente. Não houve necessidade de se usar filtros excitadores UV.

A contracoloração (fundo) con solução de permanganato de potássio não foi usada mais de 2 min. Observou-se que tempos de 3 e 4 min. reduzem substancialmente a imagem fluorescente.

Observou-se ausência de fluorescência em estregaços obtidos de culturas de Pseudomonas, Proteus, Enterobacter, Salmonella, Staphylococcus aureus, Escherichia coli, Streptococius pyogenes.

Quanto à aparelhagem, tem-se que levar en conta que o microscópio fluorescente custa de 6 a 7 vezes mais que o microscopio comum. A manutenção do aparelho do aparelho fluorescente obriga à substituição da lâmpada de vapor de mercúrio a cada 200 horas, cujo custo é considerável. O método seria perfeitamente recomendável a laboratórios que já possuam tal aparelhagem.

\section{CONCLUSOES}

1 - Existe una associação positiva entre os métodus de coloração fluorescente $e$ Ziehl-Neelsen.

2 - As diferenças entre os métodos quanto à sensibilidade foram: $7,28 \%$ e $3,17 \%$ em favor do método fluorescente nas duas áreas estudadas.

3 - As diferenças dos métodos quanto à especificidade foram despreziveis em ambas as áreas.

4-O método fluorescente, para coloração de micobactérias, é perfeitamente recomendável a laboratórios centrais, regionais ou àqueles que já possuam aparelhagem adequada.

\section{AGRADECIMENTOS}

A Profa. Dra. Sabina Lea Davidson Gotlieb pela orientação na parte estatística.

RSPUB $9 / 414$

NIERO, R. et al. /Comparison between fluorescent and Ziehl-Neelsen staining methods of pulmonary secretions] Rev. Saúde públ., S. Paulo, 12: $250-7,1978$

ABSTRACT: A comparison between fluorescent microscopy and the ZiehlNeelsen methods for evidencing resistant acid-fast bacilli in pulmonary secretions was drawn. Sensibility and specificity of each one were evaluated according to the results of the sputum culture examination. The fluorescent method showed a variety in sensibility of $7.28 \%$ and $3.17 \%$ in the studied areas. The differences in specificity were insignificant. There was a pasitive association between the two methods.

UNITERMS: Tuberculosis, diagnosis. Microscopy, fluorescence. 
NIERo, R. et al. Estudo comparatiro entre os métodos de coloração fluorescente e ZiehlNeelsen em secreções pulmonares. Rev. Saüde pübl., S. Paulo, 12:250-7, 1978.

\section{REFERENCIAS BIBLIOGRÁFICAS}

1. ANDRADE, L. Contribuição ao estudo das micobactérias - fluoromicroscopia e reação citoquímica de Dubos. $M e m$. Inst. Oswaldo Cruz, 49:7-31, 1951.

2. BERQUó. E. Análise de uma distribuição de frequiencias a duas variáveis qualitativas. In: - Broestatistica. São Paulo, Faculdade de Higiene e Saúde Pública USP, 1970. p. 31-41.

3. BOGEN, E. Detection of tubercle bacilli by fluorescence microscopy. Amer. Rev. Tuberc., 44:267-71, 1941 .

4. FREIMAN, D. \& MOKoTOFF, G. Demonstration of tubercle bacilli by fluorescence microscopy. Amer. Rev. Tuberc., $48: 435-42, \quad 1943$.

5. HIRSCH, E. W. et al. Microscopia fluorescente: sua comparação ao método de Ziehl-Neelsen e cultura. Rev. bras. Tuberc., 25:135-8, 1958.

6. HOLST, E. et al. Examination of smears for tubercle bacilli by fluorescence microscopy. Indian $J$. med. Res, 47: 495-9, 1959.

7. JOSEPH, S. W. et al. Lack of auraminerhodamine fluorescence of Runyon group IV micobacteria. Amer. Rev: resp. Dis., 95:114-5, 1967.

8. JOSEPH, S. W. \& HOUK, V. N. Evaluation and application of the fluorochrome stain for microscopic detection of mycobacteria in clinical specimens. Amer. Rev, resp. Dis., 98:1044-7. 1968.

9. KOCH, M. L. \& COTE, R. A. comparison of fluorescence microscopy with ZiehlNeelsen stain for demonstration of acid-fast bacilli in smear preparations and tissue sections. Amer. rev, Resp. Dis., 91:283-7, 1965.
10. KUPER, S. W. A. \& MAY, J. R. Detection of acid-fast organisms in tissue sections by fluorescence microscopy. $J$ Path. Bact., 79:59-68, 1960 .

11. LIND, H. E. Limitations of fluorescent microscopy for detection of acid-fast bacilli. Amer. J. clin. Path., 19:72-5. 1949.

12. MATTHAEI, E. Simplified fluorescence microscopy of tubercle bacilli. $J$. gen. Microbiol., 4:393-8, 1950.

13. MCCLURE, D. M. The development of fluorescence microscopy for tubercle bacilli and its use as an adjunct to histological routine. J. clin. Path., 6: $273-82, \quad 1953$

14. NARAIN. R. et al. Microscopy positive and microscopy negative cases of pulmonary tuberculosis. Amer. Rev, resp. Dis., $103: 761-73,1971$.

15. OLIVA, J. M. A microscopia fluorescente na pesquisa do bacilo de Koch. Arq. IBIT, $17: 163-8,1958$.

16. SILVER, H. et al. Modifications in the fluorescence microscopy-technique as applied to identification of acid-fast bacilli in tissue and bacteriological material. J. clin. Path., 19:583-7, 1966.

17. SUASSUNA, I. \& PINHEIRO, J. Comparação co método de Osol com o método de Ziehl-Neelsen para baciloscopia na tuberculose. Rer. bras, Patol. clin. $9: 48-9, \quad 1973$.

18. TRUANT, J, P. et al, Fluorescence microscopy of tubercle bacilli-stained with auramine and rhodamine, Henry Ford Hosp. Med. Bull, 10:287-96, 1962.

Recebido para publicacão em 20/09/197\% Aprovado para publicacão em 25/10/197\% 